\title{
Numerical Strategy to Simulate Seawater Ingress in RC Concrete Blocks Exposed to Wetting-Drying Cycles in Field Conditions During 19 years
}

\author{
Anthony Soive ${ }^{1}$, Véronique Baroghel-Bouny ${ }^{2}$ and Francis Lavergne ${ }^{3}$ \\ ${ }^{1}$ Cerema, UMR 7329 GEOAZUR, Pôle d'activités, avenue Albert Einstein CS 70499, 13593 Aix-en- \\ Provence cedex 3, France, anthony.soive@cerema.fr \\ ${ }^{2}$ Paris-Est University, IFSTTAR, MaSt/FM2D, F-77447 Marne-la-Vallée Cedex 2, France, ve- \\ ronique.baroghel-bouny@ifsttar.fr \\ ${ }^{3}$ Centre Technique Ouvrage d'Art, CEREMA ITM, Provins Cedex BP214 77487, France, francis.la- \\ vergne@cerema.fr
}

\begin{abstract}
Numerical results are compared to experimental data on concretes exposed in field conditions for 19 years and subjected to wetting/drying cycles in seawater after a couple of curing days. They were obtained thanks to a hydration model assuming fully hydrated concretes (19 years of curing time) and a reactive transport model in saturated conditions taking into account precipitation/dissolution of minerals and their kinetics and adsorption of ionic species on C-S-H. Numerical results show surprisingly rather good results, especially for concretes with fly ash. For OPC, although model considers average bulk porosity modifications, the experimental apparent diffusion coefficient increases much more. For concretes with silica fume, numerical results also show underestimations of total chloride content also experimental apparent diffusion coefficients are constant. Analysis of hydration calculations show that concretes are not fully hydrated after 19 years. Additional chloride content from reactions between anhydrous phases and chloride ingress may appear.
\end{abstract}

Keywords: Concrete, Chloride Binding, Seawater, Long-Term Exposure, Field Condition.

\section{Introduction}

Numerical study of reinforced concrete durability exposed to seawater in field conditions is difficult in several aspects. Environmental conditions can play a significant role in the chloride ingress (temperature, $\mathrm{RH}$, wetting-drying cycles, orientation, wind). Curing time is also important because of possible interactions between concrete and seawater as well as initial presence of chloride in mixing water (Suryavanshi and Swamy, 1996; Caré, 2008 to cite a few).

Previously reactive transport model taking into account precipitation and dissolution of mineral species with their kinetics as well as adsorption of ionic species on C-S-H were successfully used in order to simulate chloride ingress in laboratory concrete specimens (fully hydrated, controlled exposure conditions, saturated conditions) (Tran et al., 2018). However, in field conditions, concrete is not fully hydrated when they are exposed to seawater. Influence of hydration degree on chloride binding capacity of concrete is interesting.

Numerical simulations were done and compared to experimental data on concretes exposed in field conditions for 19 years and subjected to wet- ting/drying cycles in seawater after a couple of curing days. A hydration model following by a reactive transport model taking into account precipita- tion/dissolution of mineral species with their kinetics as well as adsorption of ionic species on C-S-H were used. Regarding all the phenomena to take into account, severe hypotheses were done such as saturated materials and 19 curing years. The aim of this study is 
to identify if such a severe hypothesis is sufficient in order to give a good approximation of chloride ingress.

\section{Experimental Study and Numerical Approach}

\subsection{Experimental Study}

Several concretes from the French project BHP2000 are exposed to sea- water and wettingdrying cycles in La Rochelle harbor (western French coast) since 19 years after 1 curing day (Baroghel-Bouny et al., 2013). 4 HPCs with or without silica fume (SF) and 3 normalstrength FA concretes which can appear as interesting mixtures with respect to current sustainable-de- velopment considerations were studied. All concretes described in this article were casted with the same cement (CEM I 52.5 PM ES CP2, see Table 1). Concrete mixdesign are described in Table 2.

Table 1. Chemical and mineralogical composition of the binder (\%).

\begin{tabular}{|c|c|c|c|c|c|c|c|c|}
\hline & $\mathrm{SiO}_{2}$ & $\mathrm{Al}_{2} \mathrm{O}_{3}$ & $\mathrm{Fe}_{2} \mathrm{O}_{3}$ & $\mathrm{CaO}$ & $\mathrm{MgO}$ & $\mathrm{SO}_{3}$ & $\mathrm{~K}_{2} \mathrm{O}$ & $\mathrm{Na}_{2} \mathrm{O}$ \\
\hline CEMI & 21.39 & 3.49 & 4.16 & 65.12 & 0.82 & 2.86 & 0.30 & 0.12 \\
\hline Fly Ash & 55.86 & 25.40 & 6.05 & 1.83 & 0.63 & 0.11 & 4.77 & 0.24 \\
\hline Silica Fume & 94.75 & 0.07 & 0.08 & 0.34 & 0.28 & 0.05 & 0.28 & 0.18 \\
\hline
\end{tabular}

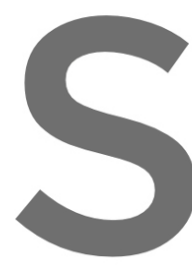

Table 2. Mix-design, along
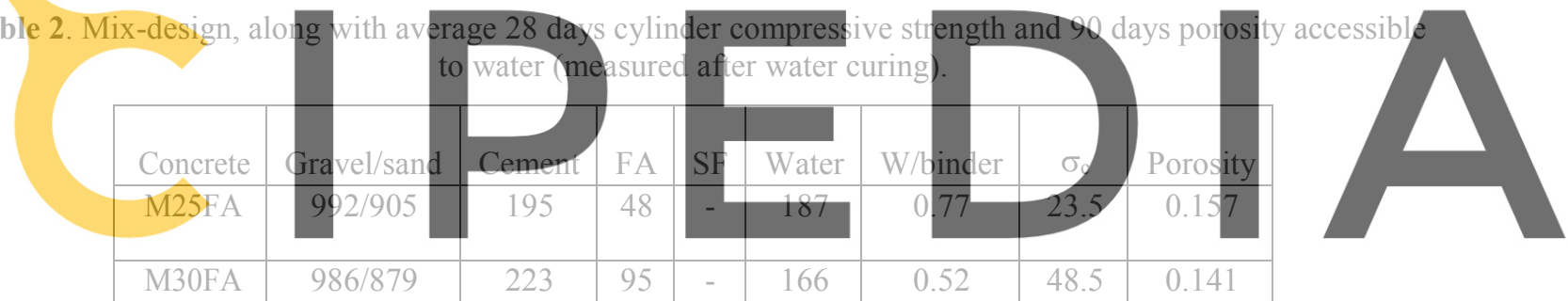

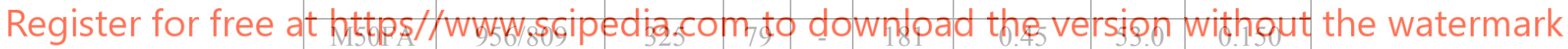

\begin{tabular}{|c|c|c|c|c|c|c|c|c|}
\hline M50 & $937 / 806$ & 410 & - & - & 197 & 0.48 & 55.5 & 0.145 \\
\hline M75 & $1025 / 808$ & 461 & - & - & 146 & 0.32 & 75.0 & 0.114 \\
\hline M75SF & $1044 / 877$ & 360 & - & 22 & 136 & 0.36 & 85.5 & 0.100 \\
\hline M100SF & $1049 / 871$ & 377 & - & 38 & 124 & 0.30 & 109.0 & 0.084 \\
\hline
\end{tabular}




\subsection{Numerical Approach}

A physically and chemically based model was developed to simulate ionic ingress in thematerials. Calculations are managed with TOUGHREACT software (Xu et al., 2012). The chemical part uses the thermodynamical database Cemdata18 (Lothenbach et al., 2019). Hydration and interstitial solution calculations precede this reactive transport simulation (see Figure 1 for the description of the simulation steps). Input data are limited to chemical and mineralogical composition of the binder, concrete mix-design, average bulk porosity and effective diffusion coefficient of concrete.

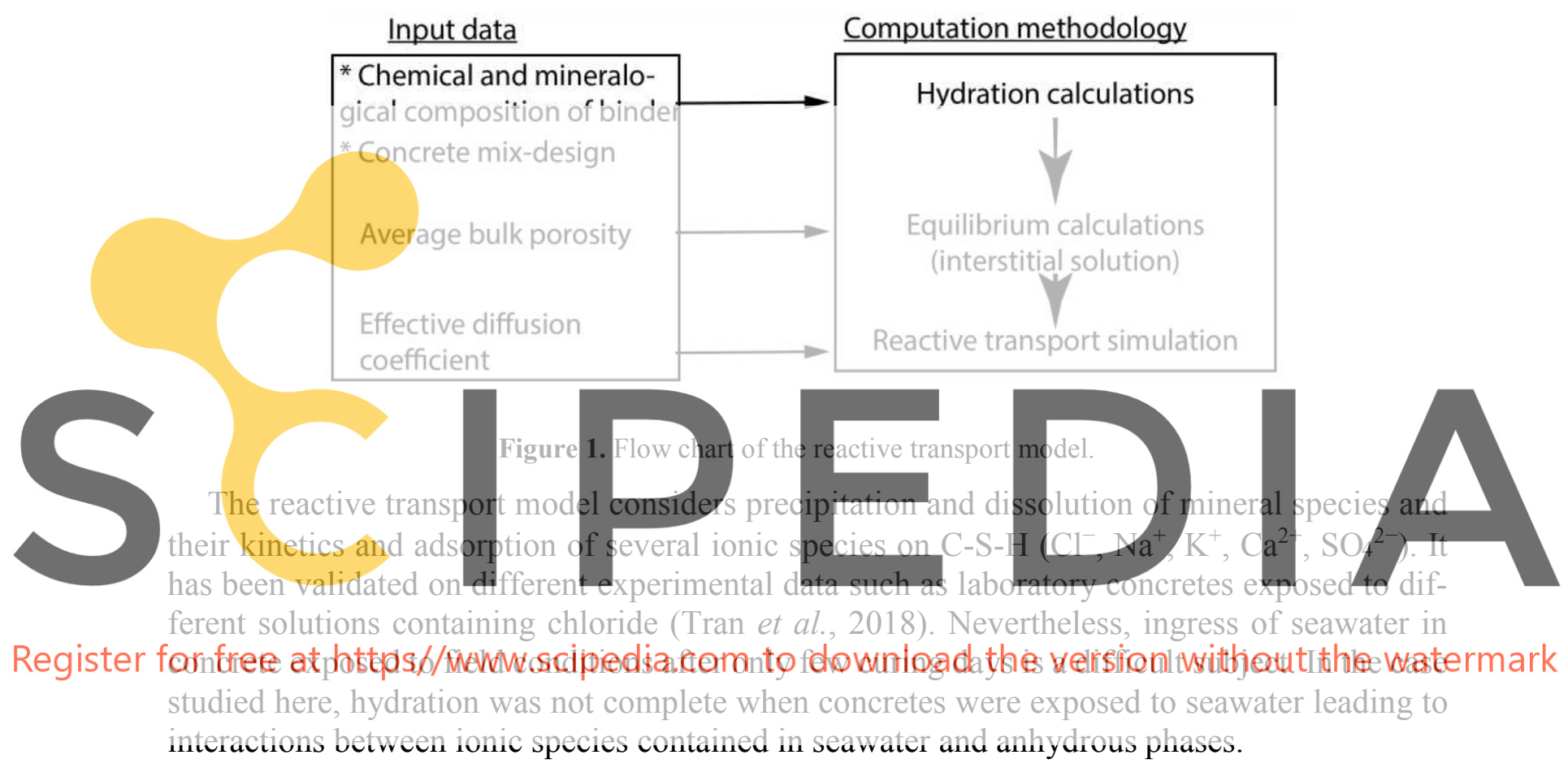


Although concretes are exposed to wetting-drying cycles, the present numerical model assumes that concrete is saturated by adopting a pure fickian approach (see Equation below). In fact, the wetting-drying cycle period is short (12 hours) and the mean value of the relative humidity in La Rochelle harbor is high (close to 67\% (Baroghel-Bouny et al., 2013)). Except for the first millimeters where carbonation can occur, this hypothesis seems to be reasonable (Soive et al., 2018).

$$
\frac{\partial \phi c_{j}}{\partial t}=\operatorname{div}\left(D_{e} \vec{\nabla} c_{j}\right)+q_{j}
$$

where $\varphi$ is the average bulk porosity, $\mathrm{c}_{\mathrm{j}}$ the concentration of species $\mathrm{j}$ [mol. $\mathrm{m}^{-3}$ of solution], $D_{e}$ the effective diffusion coefficient $\left[\mathrm{m}^{2} . \mathrm{s}^{-1}\right]$ (supposed to be equal for all species) and $\mathrm{q}_{\mathrm{j}}$ source or sink term $\left[\mathrm{mol} \cdot \mathrm{m}^{-3} \cdot \mathrm{s}^{-1}\right]$. Ions can chemically react with the matrix to precipitate minerals (e.g. ettringite, brucite, Kuzel and Friedel's salts) or to dissolve others (portlandite, monosulfate). They also can be bound (adsorbed or absorbed) to the surface of the matrix. As described in previous studies (Baroghel-Bouny et al., 2013; Soive et al., 2018), all mineral precipitation/dissolution kinetics also need to be taken into account. In addition, the effective diffusion coefficient $\mathrm{D}_{\mathrm{e}}$ can evolve with average bulk porosity value change as follows:
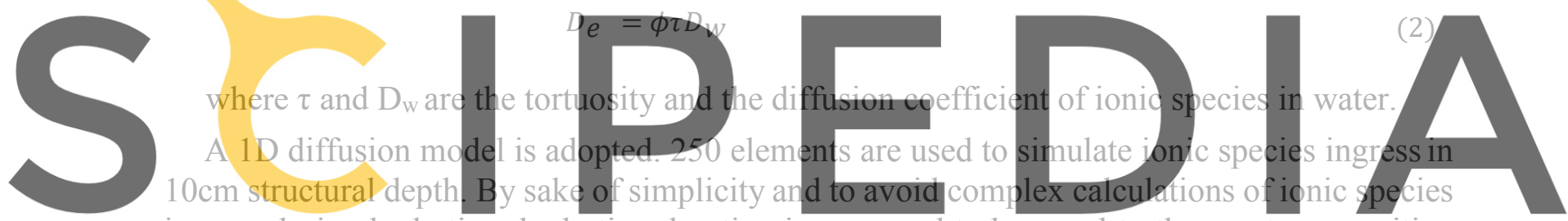
ingress during hydration, hydration duration is supposed to be equal to the greater exposition tween hydration and seawater ingress at first time exposure. Chemical reactions between seawater and anhydrous species are not considered.

\section{Results and Discussion}

Total chloride content profiles were measured after 2, 4, 10, 16 and 19 years of exposure. Comparison between experimental data and numerical results with 19 curing years is exposed in Figure 2. Knowing the limited number of input data and the difficulty to catch all the phenomena, the numerical simulations show hopeful results.

Three aspects can be underlined: the "convection zone", the evolution of apparent diffusion coefficient as a function of time and possible chemical reactions between chloride and anhydrous phases. 

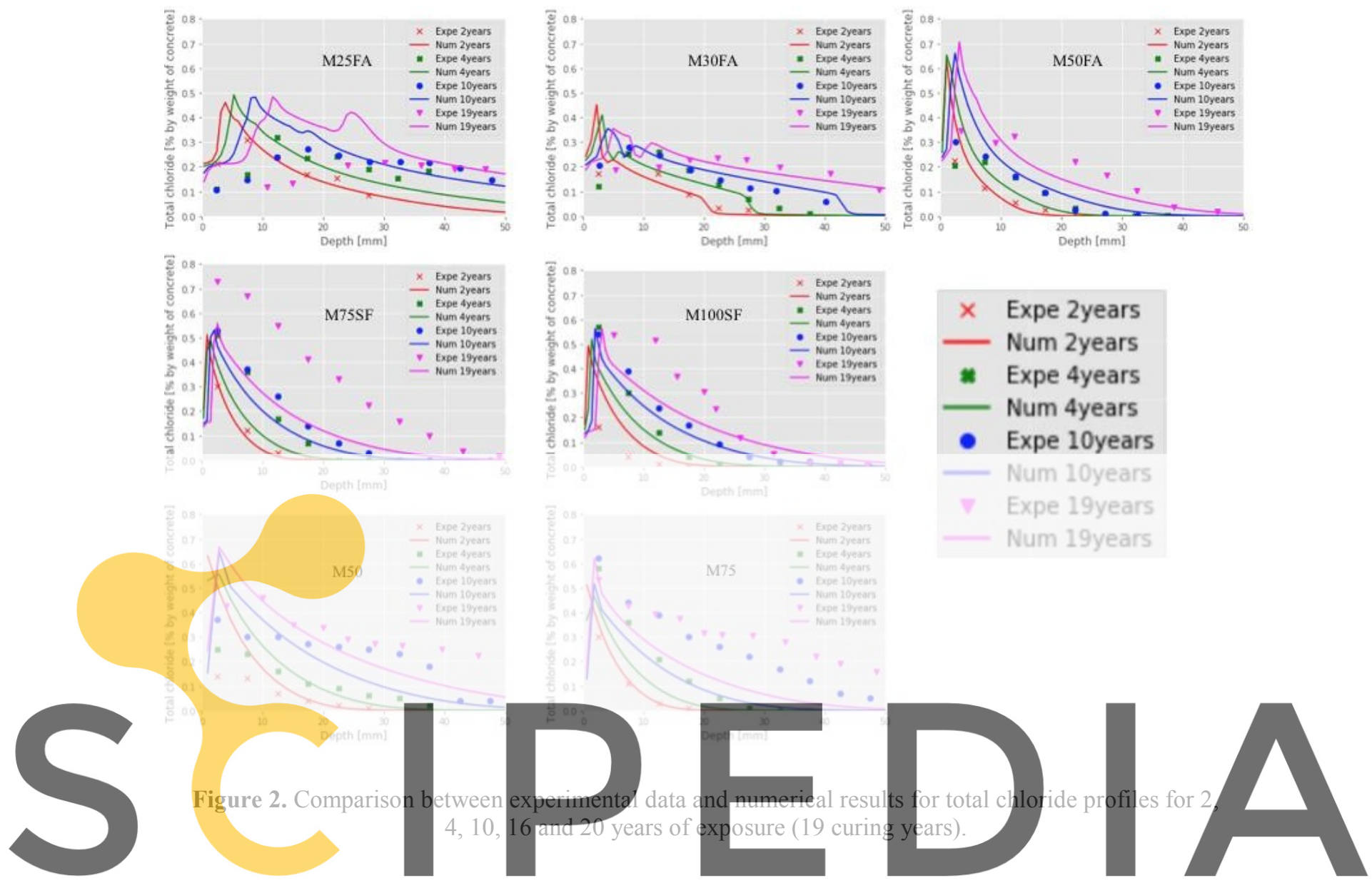

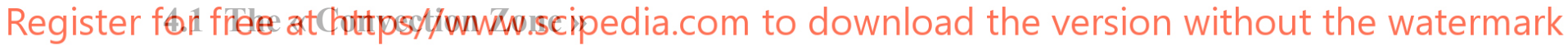

For concretes with fly ash (M25FA, M30FA, M50FA), results are rather good except in the first miliimeters and although numerical model does not consider wetting/drying cycies. The depth at which total chloride content is maximum is to underline. This zone is often associated with the "convection zone". Nevertheless, even with a model that simulate the ingress of ionic species in saturated concrete such as the present one, this phenomenon is observed. As reported by Jakobsen et al. (2016), chemical and mineral zonation appear. Three zones (magnesium, sulfur and chloride-rich zones) are found irrespective of the age, location or binder composition. Figure 3 show that the model can qualitatively simulate these zones. However, in this "convection zone", results are very different from experimental data. The use of a model considering wetting-drying cycles is necessary in order to catch phenomena in this zone (convection, local chloride concentration increase). 

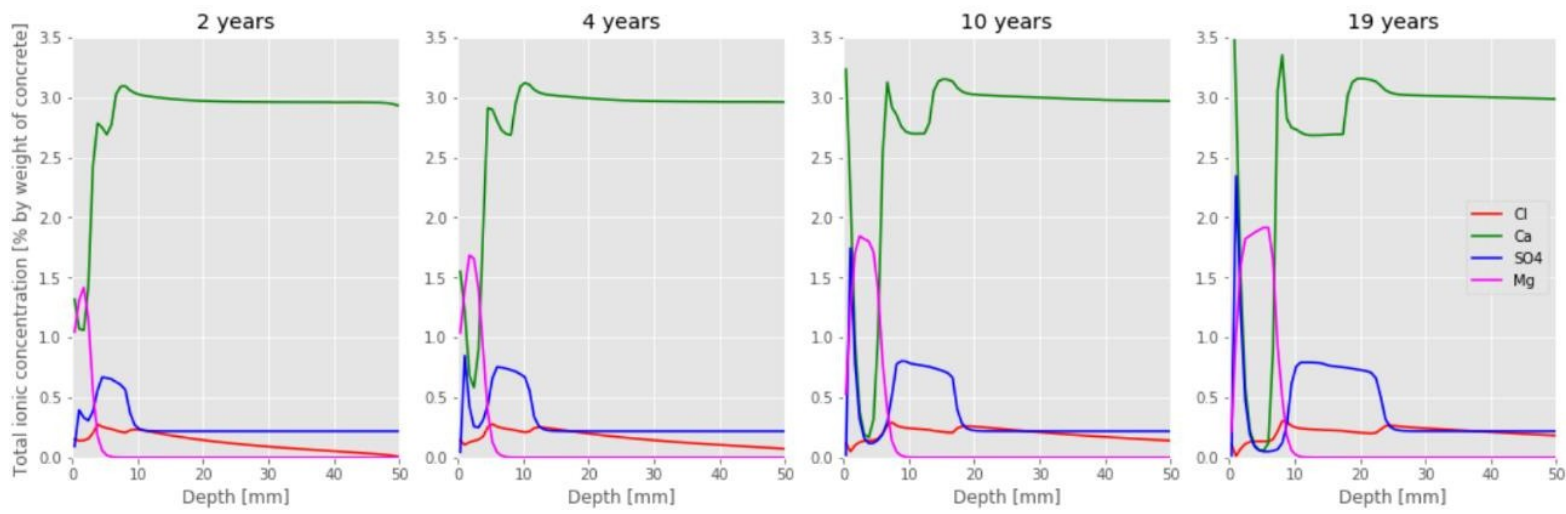

Figure 3. Ionic species ingress after 2, 4, 10, 16 and 20 years of exposure for M25FA (19 curing years)

\subsection{The Evolution of Apparent Diffusion Coefficient with Time}

For OPC (M50, M75), whereas profiles are close to experimental data after 2-year exposure, total chloride contents are underestimated for greater exposure durations. These differences can be partly explained by the fact that apparent diffusion coefficient (which includes both effective diffusion and binding) for M50 and M75 increases with time (by inverse analysis calculations on experimental data) from $1.610^{-13}$ to $210^{-13} \mathrm{~m}^{2} \cdot \mathrm{s}^{-1}$ and $3.610^{-13}$ to $1.610^{-12} \mathrm{~m}^{2} \cdot \mathrm{s}^{-1}$, respec-

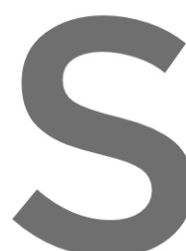
tively (see Figure 4). The rosity) due to mineral d the evolution of chlorid than the one computed. termine if other phenom ences between concrete first miltimeters and deeper.
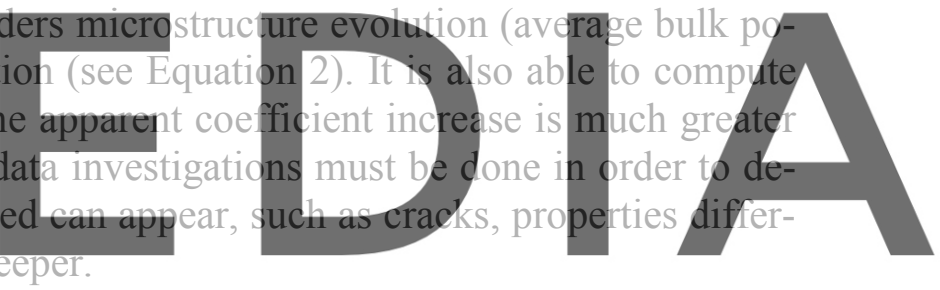

Register for free at https//www.scipedia.com to download the version without the watermark

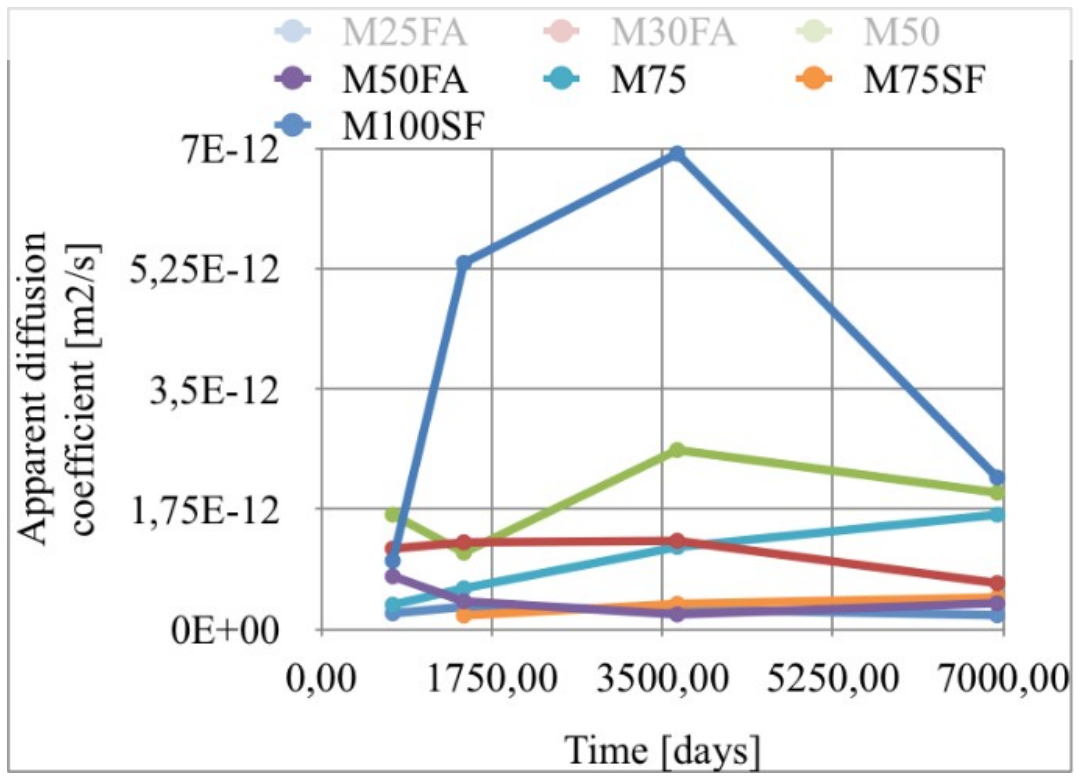

Figure 4. Apparent diffusion coefficient calculations by inverse analysis. 


\subsection{Possible Chemical Reactions between Chloride and Anhydrous Phases}

For concretes with silica fume (M75SF, M100SF), underestimations ap- pear after 2-year exposure. Nevertheless, as can be seen in Figure 4 and contrary to M50 and M75, the apparent diffusion coefficients are constant. By analyzing hydration results of M75SF thanks to a hydration model developed at Cerema (Lavergne et al., 2018) (see Figure 5), results show that anhydrous phases are still present after 19 curing years (6500 days) as well as a lack of monosulfate. These results confirm that hydration is slower for these concretes. However, presence of seawater can affect the hydration process by accelerating hydration or precipitating minerals containing chloride (Friedel's salt) (Li et al., 2018). Unfortunately, the present model is not able to calculate chloride ingress in concretes that continue to hydrate.

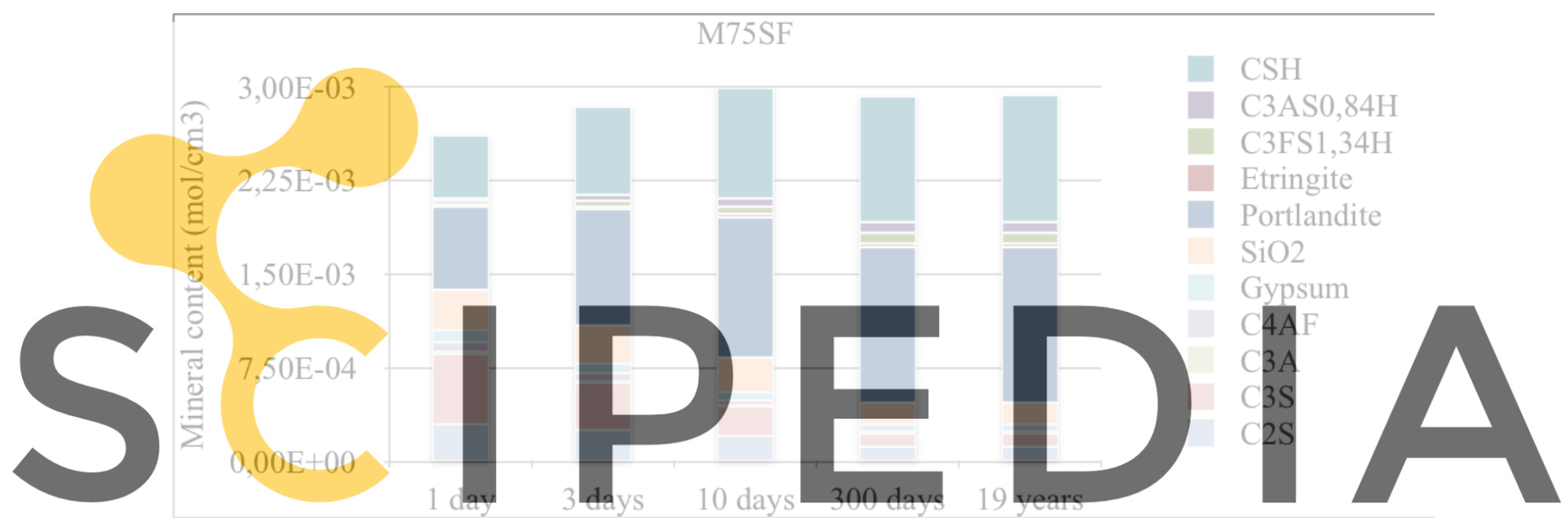

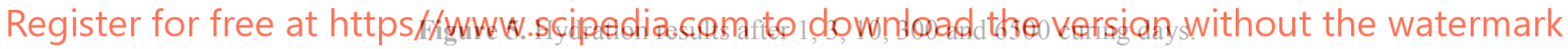

\section{Conclusion}

Experimental data on concretes exposed to tidal zone in field conditions for 19 years and subjected to wetting-drying cycles in seawater after a couple of curing days were compared to numerical results. Two OPCs, three concretes with fly ash and two concretes with silica fume with the same cement were studied. The numerical results were obtained thanks to a hydration model and a reactive transport model considering precipitation/dissolution of minerals and their kinetics and adsorption of ionic species on C-S-H.

A pure fickian approach in saturated materials is assumed. In addition, due to difficulties to model interactions between ingress of ionic species and hydration, numerical model assumes that hydration lasts for 19 years (last measurement value). 
Knowing the limited number of input data and the difficulty to catch all the phenomena, the numerical simulations show hopeful results, especially for concrete with fly ash. In addition, the model can qualitatively simulate chemical and mineral zonation (magnesium, sulfur and chloride-rich zones) as reported in the literature. For OPC and concretes with silica fume, numerical results underestimate chloride content. For OPC, although numerical model considers porosity change due to mineral precipitation/dissolution, it is not able to simulate increase of apparent diffusion coefficient as observed on experimental data. Further investigations must be done in order to observe if cracks are visible. For concretes with silica fume, underestimation cannot be fully explained yet. One explanation can be the lack of additional chloride content coming from reactions between chloride and remaining anhydrous phases. Indeed, by analyzing results of hydration calculations, results show that anhydrous phases are still present even after 19 years and that additional chloride content can exist.

\section{ORCID}

Previous the references list, the authors' ORCID must be provided, in 10pt Times New Roman, as in the example: Anthony Soive: https://orcid.org/0000-0002-2368-6848

Véronique Baroghle-Bouny:

Francis Lavergne: https://orcid.org/0000-0001-6984-3784

References

Baroghel-Bouny, V., Dierkens, M., Wang, X., Soive, A., Saillio, M., Thiery, M. and Thauvin, B. (2013). Ageing and durability of concrete in lab and in field conditions: Investigation of chloride penetration. Journal of Sustainable Caré, S. (2008). Effect of temperatu Building Materials, $22(7)$

Jakobsen, U. H., De Weetd Concrete Research, 8

Lavergne, F., Ben Fraj,
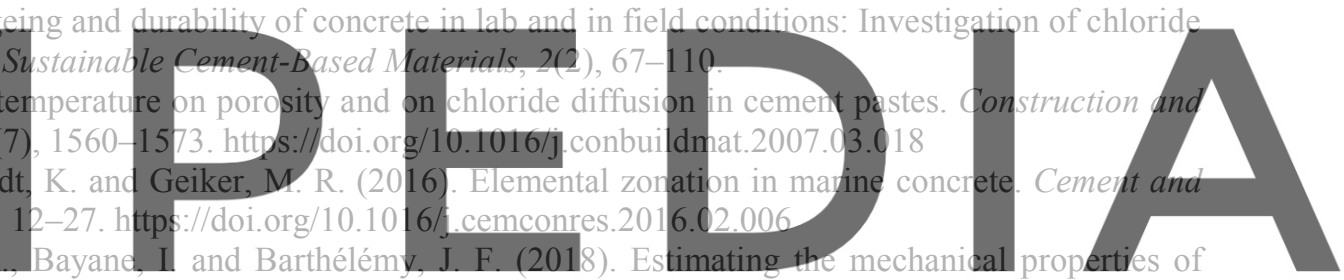

hydrating blended cementitious materials: An investigation based on micromechanics. Cement and Concrete

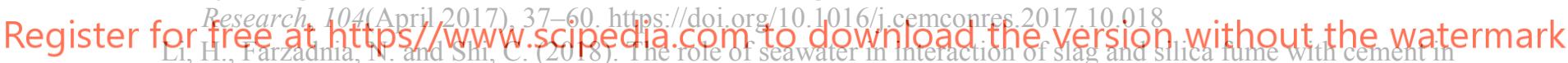
low water-to-binder ratio pastes at the early age of hydration. Construction and Building Materials. https://doi.org/10.1016/j.conbuildmat.2018.07.091

Lothenbach, B., Kulik, D. A., Matschei, T., Balonis, M., Baquerizo, L., Dilnesa, B. and Myers, R. J. (2019). Cemdata18: A chemical thermodynamic database for hydrated Portland cements and alkali-activated materials. Cement and Concrete Research, 115(October 2018), 472-506. https://doi.org/10.1016/j.cemconres.2018.04.018

Soive, A., Tran, V.-Q. and Baroghel-bouny, V. (2018). Requirements and possible simplifications for multi-ionic transport models - Case of concrete subjected to wetting-drying cycles in marine environment. Construction and Building Materials, 164.

Suryavanshi, A. K. and Swamy, R. N. (1996). Stability of Friedel's salt in carbonated concrete structural elements. Cement and Concrete Research, 26(5), 729-741.

Tran, V.-Q., Soive, A. and Baroghel-bouny, V. (2018). Modelisation of chloride reactive transport in concrete including thermodynamic equilibrium, kinetic control and surface complexation. Cement and Concrete Research, 110(January 2017), 70-85.

Xu, T., Spycher, N. and Sonnenthal, E. (2012). TOUGHREACT User's Guide: A Simulation Program for Nonisothermal Multiphase Reactive Transport in Variably Saturated Geologic Media, version 2.0. Lawrence Berkeley .... 